\title{
Multiple oncogenic viruses identified in Ocular surface squamous neoplasia in HIV-1 patients
}

Kenneth O Simbiri', Masanao Murakami ${ }^{6}$, Michael Feldman², Andrew P Steenhoff ${ }^{3}$, Oathokwa Nkomazana ${ }^{4}$, Gregory Bisson ${ }^{5}$, Erle S Robertson ${ }^{1 *}$

\begin{abstract}
Background: Ocular surface squamous neoplasia (OSSN) is a rare cancer that has increased in incidence with the HIV pandemic in Africa. The underlying cause of this cancer in HIV-infected patients from Botswana is not well defined.

Results: Tissues were obtained from 28 OSSN and 8 pterygia patients. The tissues analyzed from OSSN patients were $83 \%$ positive for EBV, $75 \%$ were HPV positive, 70\% were KSHV positive, $75 \%$ were HSV-1/2 positive, and $61 \%$ were CMV positive by PCR. Tissues from pterygium patients were $88 \%$ positive for EBV, $75 \%$ were HPV positive, $50 \%$ were KSHV positive, and 60\% were CMV positive. None of the patients were JC or BK positive. In situ hybridization and immunohistochemistry analyses further identified HPV, EBV, and KSHV in a subset of the tissue samples.

Conclusion: We identified the known oncogenic viruses HPV, KSHV, and EBV in OSSN and pterygia tissues. The presence of these tumor viruses in OSSN suggests that they may contribute to the development of this malignancy in the HIV population. Further studies are necessary to characterize the molecular mechanisms associated with viral antigens and their potential role in the development of OSSN.
\end{abstract}

\section{Background}

Ocular surface squamous neoplasia (OSSN) is a conjunctival or corneal neoplastic growth that encompasses the conditions of simple dysplasia to conjunctival intraepithelial neoplasia (CIN) to invasive squamous cell carcinoma [1]. Similar to cancer of the cervix, it has a relatively high rate of recurrence after treatment and may metastasize [2]. OSSN has gained interest in the past few years in its association with the HIV pandemic and its increase in incidence is collinear with the increase in HIV [3]. Prior to the HIV pandemic, OSSN was noted to occur predominantly in the elderly for whom it is the third most common oculoorbital tumor after melanoma and lymphoma [4,5]. In addition to advanced age and male sex, other risk factors linked to its pathogenesis have included ultraviolet light $B$ rays and mutation of the p53 tumor suppressor gene [6], immunosuppression in organ transplant recipients [7],

\footnotetext{
* Correspondence: erle@mail.med.upenn.edu

'Department of Microbiology, and Abramson Comprehensive Cancer Center, Tumor Virology Program, University of Pennsylvania, 202A Johnson Pavilion, 3610 Hamilton Walk, Philadelphia, PA 19104-6076, USA
}

cigarette smoking, and in some settings, HPV infection $[3,8]$. In Africa, OSSN is becoming more common, more aggressive, and more likely to affect young people, especially females [6].

In parallel with the dramatic increase of HIV in Africa, several countries have noted a sharp rise in the incidence of OSSN in HIV infected individuals such that OSSN is currently the most common ocular tumor among adults in Africa [6,9]. Africa has the highest rate of HPV infection in the world, with an age-adjusted prevalence of $25.6 \%$ in women aged $15-74$ years, followed by South America (14.3\%), Asia (8.7\%), and Europe (5.2\%) [10]. In 2006, Waddell et al. investigated the role of HIV infection in the etiology of corneo-conjunctival intraepithelial neoplasia (CIN) and carcinoma [11]. The prevalence of HIV infection in these cases was $64 \%$ compared to $31 \%$ in controls [11]. These findings demonstrated a strong association between increased incidence of OSSN and HIV-1 infection as applied to all tumor stages in Uganda. HIV-positive participants were markedly immunosuppressed at the time of diagnosis and their early mortality was high [11]. The majority of 
the tumors were in the interpalpebral area of the conjunctiva, which supports the concept of UV radiation as a co-factor in the etiology of OSSN [11].

Pterygium is a raised benign growth on the eye that is most often directly related to over-exposure to the sun and dry, dusty conditions may also be a factor [12]. Pterygium in the conjunctiva is characterized by elastotic degeneration of collagen and fibrovascular proliferation, and in some cases by "wing-like" conjunctival overgrowth of the cornea [13]. Some studies have investigated human papillomavirus (HPV) as a risk factor for the development of pterygia [14,15]. Interestingly, recent studies have shown that pterygia can develop into OSSN, and thus may be considered a pre-malignant form of OSSN [16].

The aim of this study was to identify the viral etiologic agent(s) associated with OSSN in the HIV-infected population in Botswana. There are numerous examples of associated malignancies in the HIV population, which include CNS lymphomas with greater than 95\% Epstein Barr Virus (EBV) positivity [17], pleural effusion lymphomas which are usually co-infected with both tumor gammaherpesviruses EBV and Kaposi's sarcoma associated herpes virus (KSHV) [18,19], AIDS associated B and T cell lymphomas [20], Kaposi's sarcoma (KS)[21], Burkitt's lymphoma (BL) [22], anogenital carcinomas and papillomas [23], oral cancers [23,24] osteosarcomas [25] mesotheliomas [25] and brain cancers $[2,18,21,23,26-28]$. Also, the oncogenic papova virus Human papillomavirus (HPV) infects keratinocytes causing benign and malignant tumors [1]. HPV proteins E6 and E7 are oncogenic and have been associated with cell immortalization and antiapoptotic effects. The HPV types 6, 11, 16, 18 and 33 have been identified in benign and malignant conjunctival lesions [3].

The role of chronic latent viruses and their intermolecular interactions in combination with other environmental factors in the context of HIV infection is likely to be important for initiating and maintaining HIV-associated malignancies. However, a causal role for these viruses is difficult to ascertain at this time. Nevertheless, infection with a range of viruses from the herspesviridae family including HSV, HCMV, EBV, and KSHV may contribute to the oncogenic process in OSSN, as has been observed with other human cancers [29].

\section{Methods}

\section{Patients}

HIV-1 infected patients with conjunctival lesions seen at Princess Marina Hospital, Gaborone, Botswana from April 112007 to April 142008 were enrolled in this study (IRB \#805049 and Ministry of Health, Botswana REF NO: PPME 13/18/1 Vol III 141). Briefly, patients were identified by an ophthalmologist in the tertiary care ophthalmology clinic at Princess Marina Hospital which serves as the referral center for southern Botswana. All HIV-1 positive patients diagnosed using a HIV-ELISA (Abbott Laboratories, Hoofddorp, the Netherlands) with clinical features suggestive of OSSN or pterygium were enrolled the day before surgery. Written consent was obtained from each subject in either Setswana or English (according to subject's preference). Tissue specimens obtained in the ophthalmology operating room were divided into two pieces by the ophthalmology surgeon - one piece was sent for histopathologic analysis and the other was immediately placed in tissue transport medium for shipment to the University of Pennsylvania viral oncology laboratory. Histologic confirmation of each clinical diagnosis was obtained from the Botswana National Health Laboratory's histopathologist. 39 patients participated in the study, however tissue samples of varying sizes were obtained from only 36 cases. Tissues from patients included in this study were 28 whose clinical diagnosis was OSSN and 8 with pterygia (Table 1 ). Only patients who signed the University of Pennsylvania and Botswana Ministry of Health Institutional Review Board consent forms were included in this study. In this study all patients were enrolled from the Botswana HIV clinic. Therefore we were not able to obtain conjunctiva controls from HIV1 negative patients or those diagnosed with OSSN and pterygia identified as HIV negative.

\section{DNA extraction, in situ hybridization and immunohistochemistry of tissue samples}

Total cellular DNA was extracted from fresh OSSN and pterygia tissues by digestion with proteinase $\mathrm{K}$ and phenol-chloroform extraction as previously described [30].

PCR analysis was performed as previously described [31-35] with each virus specific primer (see Figure 1C).

To support our PCR findings for the presence of HPV, $\mathrm{EBV}$, and KSHV in tissues we performed in situ hybridization and immunohistochemistry on $5 \mu \mathrm{m}$ thick paraffinembedded sections to detect virus specific antigens. We noted alignment with the probes for HPV-16-L1 at 481511 bp (accession DQ155283), EBV-EBER at 1-26 bp (accession J02078) and for KSHV-ORF-72 at 201-220 bp (accession 009333). In situ hybridization probes for HPV16 or 18 [36], EBV-EBER [30], and KSHV-ORF-72 [34] were labeled with digoxigenin-ddUTP (Dig) using a commercial kit (Roche Inc., Indianapolis, IN) and used as described previously [37]. We used commercial antibodies HPV 16-L1 and HPV 18-E6 (DAKO Inc., Carpentaria, CA), and monoclonal antibody S12 for EBV-LMP1, and monoclonal antibody derived from KSHV encoded LANA for immunohistochemistry [38]. Results from the ISH and IHC were analyzed by a licensed histopathologist at the University of Pennsylvania, School of Medicine. 
Table 1 Patient characteristics

\begin{tabular}{|c|c|c|c|c|c|c|c|c|}
\hline Case \# & Diagnosis & Sex & Age & CD4 count & HIV Viral load & Affected Eye & ARV Status & Histology Results \\
\hline 1 & OSSN & M & 45 & 40 & $<400$ & Right & + & SCC \\
\hline 2 & Pterygium & M & 49 & 373 & $<400$ & Left & + & Pterygium \\
\hline 3 & OSSN & M & 39 & 64 & $<400$ & Right & + & Pterygium \\
\hline 4 & OSSN & M & 32 & 521 & ND & Right & & SCC \\
\hline 5 & OSSN & $\mathrm{F}$ & 47 & 44 & ND & Right & + & SCC \\
\hline 6 & OSSN & M & 43 & 174 & 120,000 & Right & & SCC \\
\hline$* 7$ & Pterygium & $\mathrm{F}$ & 29 & ND & ND & Right & + & Pterygium \\
\hline 8 & OSSN & $\mathrm{F}$ & 42 & 134 & 120,000 & Left & + & SCC \\
\hline 9 & OSSN & $\mathrm{F}$ & 27 & 171 & $<400$ & Left & + & NA \\
\hline$* 10$ & OSSN & M & 40 & ND & $<400$ & Right & & Severe dysplasia \\
\hline 11 & OSSN & M & 38 & 326 & $<400$ & Left & + & Severe dysplasia \\
\hline 12 & OSSN & $F$ & 22 & 457 & $\mathrm{ND}$ & - & & NA \\
\hline 13 & OSSN & $F$ & 44 & ND & $<400$ & Left & + & SCC \\
\hline 14 & OSSN & $F$ & 39 & 200 & $<400$ & Left & + & Pterygium \\
\hline 15 & Pterygium & $\mathrm{F}$ & 38 & 725 & ND & Left & & Pterygium \\
\hline 16 & Pterygium & $\mathrm{F}$ & 40 & 600 & ND & Left & & Pterygium \\
\hline 17 & Pterygium & $\mathrm{F}$ & 38 & 491 & ND & Left & & Pterygium \\
\hline 18 & OSSN & $F$ & 44 & 314 & ND & Left & & NA \\
\hline 19 & OSSN & $\mathrm{F}$ & 37 & 56 & $<400$ & Right & + & Pterygium \\
\hline$* 20$ & OSSN & M & 48 & 21 & $<400$ & Right & + & SSCC \\
\hline 21 & OSSN & $\mathrm{F}$ & 49 & ND & ND & Right & & NA \\
\hline 22 & OSSN & $\mathrm{F}$ & 30 & 90 & ND & Right & & SSCC \\
\hline 23 & OSSN & $F$ & 36 & 220 & $<400$ & Right & + & Severe dysplasia \\
\hline 24 & OSSN & $\mathrm{F}$ & 35 & ND & 644,000 & Right & + & Mild dysplasia \\
\hline 25 & Pterygium & $F$ & 39 & 293 & $<400$ & Left & + & Pterygium \\
\hline 26 & Pterygium & M & 47 & 546 & $<400$ & Right & & Pterygium \\
\hline 27 & Pterygium & $\mathrm{F}$ & 31 & 113 & ND & Left & + & Pterygium \\
\hline 28 & OSSN & M & 50 & 87 & $<400$ & Right & + & SCC \\
\hline 29 & OSSN & $\mathrm{F}$ & 34 & 192 & ND & Left & & SCC \\
\hline 30 & Pterygium & $\mathrm{F}$ & 29 & 70 & $<400$ & Right & + & Pterygium \\
\hline 31 & OSSN & M & 45 & 62 & 17,000 & Left & + & NA \\
\hline 32 & OSSN & $\mathrm{F}$ & 28 & 107 & $<400$ & Left & + & Severe dysplasia \\
\hline 33 & OSSN & $\mathrm{F}$ & 42 & 236 & 342 & Left & & Pterygium \\
\hline 34 & OSSN & M & 33 & 94 & 81,972 & Left & + & SCC \\
\hline 35 & OSSN & M & 40 & 64 & 685,000 & Right & + & Cancer in situ \\
\hline 36 & OSSN & $\mathrm{F}$ & 36 & 38 & 200,000 & Right & + & NA \\
\hline 37 & OSSN & $\mathrm{F}$ & 49 & ND & ND & Right & & Severe dysplasia \\
\hline 38 & OSSN & $\mathrm{F}$ & 24 & 31 & ND & Left & + & Moderate dysplasia \\
\hline 39 & OSSN & $\mathrm{F}$ & 44 & 121 & ND & Right & & SCC \\
\hline
\end{tabular}

* Tissue not available, NA - Not available

The table shows patient diagnosis, sex, age on entering study, CD4 counts, viral load, the eye affected, the retroviral therapy status of each patient, and histology results. Tissues were not obtained from 3 patients and indicated with an asterisk. Patients \#s 3, 14, 19, and 33 were diagnosed as OSSN but histology results indicated that they were pterygia. 

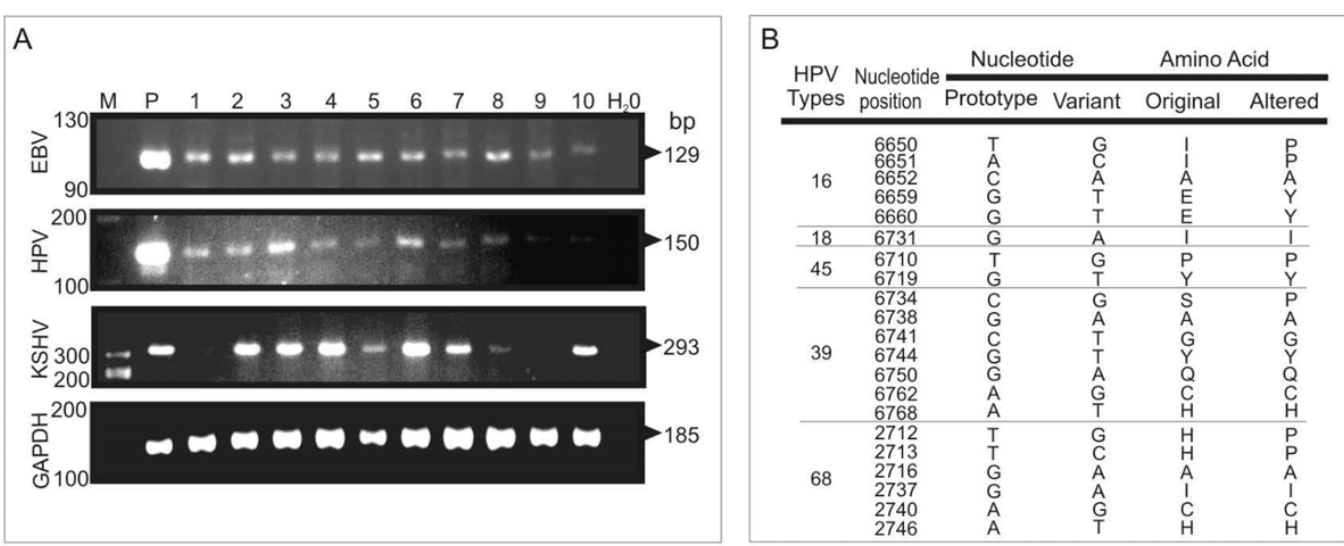

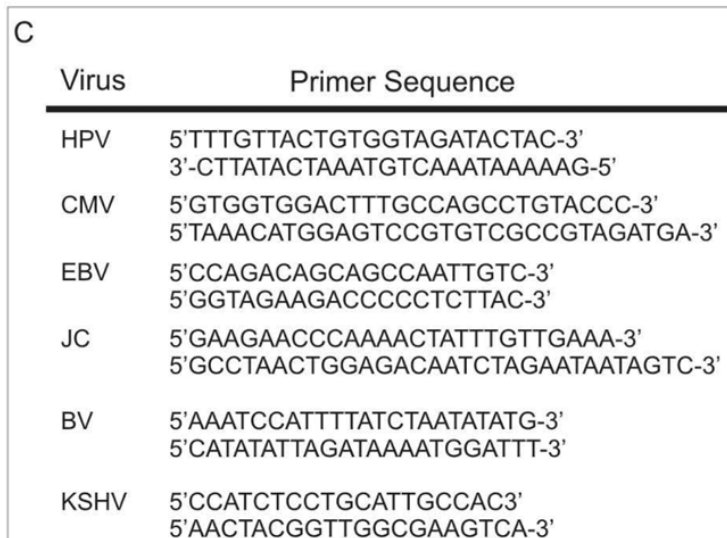

Probes

HPV-16 5'GCAAACCACCTATAGGGGAACACTGGGGCA

L1

L1

Size

HPV-18 5'TGGTTCAGGCTGGATTGCGTCGCAAGCCCA

EBER

EBV- 5' AGACACCGTCCTCACCACCCGGGACT

ORF-72

KSHV- 5'TCTGACTCTGTATTTGGGACC

34

Figure 1 PCR analysis of OSSN for detection of human viruses. A. Representative PCR analysis of tumor virus detection from OSSN tumor samples. For EBV PCR, LCL-2 $10^{5}$ cells which contain 20-50 copies of EBV per genome were used as positive control and distilled water as control for PCR mix. For HPV, Hela $10^{5}$ cells which contain 10-20 copies of HPV-18 per genome were used as positive control and distilled water as control for PCR mix. Similarly for KSHV we used BCBL1 cells which contain 30-50 copies of KSHV per genome as positive control and distilled water as control for PCR mix. The PCR products are shown after electrophoresis on a 3\% agarose gel containing $100 \mathrm{ng} / \mathrm{ml}$ ethidium bromide. PCR product size for each virus type is shown on the right side. We show representative gels showing the PCR results of which EBV was detected in $83 \%$ of the samples, HPV in $75 \%$ of the samples, KSHV in $70 \%$ of the samples and CMV in $61 \%$ of the samples. We did not detect JC and BK virus in any sample. B. Representative point mutations in HPV-L1 nucleotide and amino acid sequence variation in OSSN biopsies. We detected HPV-16, 18, 45, 39, and 68 isolates. As shown, the changes were mainly missense and nonsense mutations. C. Shows the primer sequences used in the PCR analysis of the oncogenic viruses in OSSN and pterygia tissues and probes used for in situ hybridization.

\section{DNA Sequencing}

To determine the HPV types and variants, analysis of the PCR products were directly sequenced on an automated sequencer according to manufacturer's protocol (Applied Biosystems Inc., Foster City, CA). Briefly, HPV PCR products with consensus primers were prepared and the reaction was run under standard cycle conditions of $96^{\circ} \mathrm{C}$ for 10 seconds, $55^{\circ} \mathrm{C}$ for 5 seconds, and $60^{\circ} \mathrm{C}$ for 4 minutes for a total of 25 cycles. The PCR amplicons were then ethanol precipitated, dried briefly in a speed-vacuum, resuspended in Hi Di formamide and loaded onto the 3730 DNA analyzer (Applied Biosytems Inc., Foster City, CA) for capillary electrophoresis and analysis. Sequence analysis was done using Applied Biosystems Sequence Analysis Software v5.3.1. The sequences 
were compared to the specific HPV prototype sequences in GenBank.

\section{Results}

Patients were HIV positive and predominantly female

Tissue samples, sera, and plasma were collected from 39 patients with a diagnosis of OSSN or pterygium from Princess Marina Hospital in Botswana (Table 1). All patients were HIV-1 positive and 24 were on antiretroviral therapy (ARV) at the time of the study. Of the 39 cases, 13 were male and 26 were female, 30 had OSSN, and 9 had pterygia. The patients were young with 38 cases under the age of 50 years old. CD4 counts were available for 32 patients and 20 patients had counts below 200 cells $/ \mathrm{ml}$ when ARVs were started. Only 36 tissue samples were received for processing-28 OSSN and 8 pterygia. Histological analysis was obtained on the samples except for six where no histological information was provided, and indicated that some of the tumors were squamous cell carcinoma (SCC), surface squamous cell carcinoma (SSCC), pterygia, severe dysplasia, moderate, and mild dysplasia (Table 1). No tissues were obtained from cases \# 7, 10, and 20 and so no further analyses were done. The patients on ARVs had viral loads that were generally low. However, a few had high copies (>100,000 copies $/ \mathrm{ml}$ ) and were patients started on ARVs therapy relatively recently. Viral load analysis was not completed for fifteen patients. No cases were bilateral, however there was a preponderance for the left eye for the few pterygium cases. The photographs represent example showing a patient with OSSN (2A), and a closer view (2B). $\mathrm{H}$ and $\mathrm{E}$ staining of OSSN tissues typically shows in situ carcinoma characterized by full thickness changes in nuclear to cytoplasm ratio, nuclear pleomorphism, dyskeratotic cells, and the presence of koilocytes from HPV infection that could be seen in some lesions (Figure 2C).

\section{PCR analysis detected DNA from oncogenic viruses in OSSN tissues}

We performed PCR analysis on all tissues obtained to determine whether any tumor viruses are associated with OSSN. As shown in table 2, 30 (83\%) cases were EBV positive, 27 (75\%) cases were HPV positive, 25 (70\%) cases were KSHV positive, 22 (61\%) cases were CMV positive, 25 (70\%) were HSV $1 / 2$ positive, and none of the patients had BK or JC. Using specific primers for identification of specific HPV types, we detected HPV- 6, 11, 16, 18, 31, and 33 (Table 3). The table shows that in both OSSN and pterygia samples HPV-11, 16, and 18 were the most common. HPV-6, 31, and 33 were rare and not detected in pterygia samples. Results from the PCR analyses are depicted by the representative sample of cases tested for EBV, HPV and KSHV (Figure 1A). It is to be noted that a majority of the cases tested were positive for all three oncogenic viruses, albeit with different levels of intensity based on difference in viral loads, cancer stage, and tissue size from which the DNA was extracted. Some of the tissues were co-infected with HPV/EBV/KSHV in different combinations as determined by PCR (Table 2, and Figure 1). Interestingly, the data showed that the majority of the samples had signals for both HPV-16 and 18 with only $21 \%$ of OSSN positive for HPV-6 and $46 \%$ with signals for HPV-11 (Table 3). Moreover, 25\% of OSSN tissues were positive for HPV-31 and 4\% of OSSN tissues were positive for HPV-33 (Table 3). Therefore, in the OSSN tissues from immunocompromised patients there was a high degree of co-infection with multiple oncogenic viruses as indicated by PCR, IHC, and ISH (Table 4). Importantly, it should also be noted that all PCR analyses done on archival tissues were negative or inconclusive and therefore were not included in this study (data not shown). This was likely due to the inadequate or compromised conditions of the stored tissues.

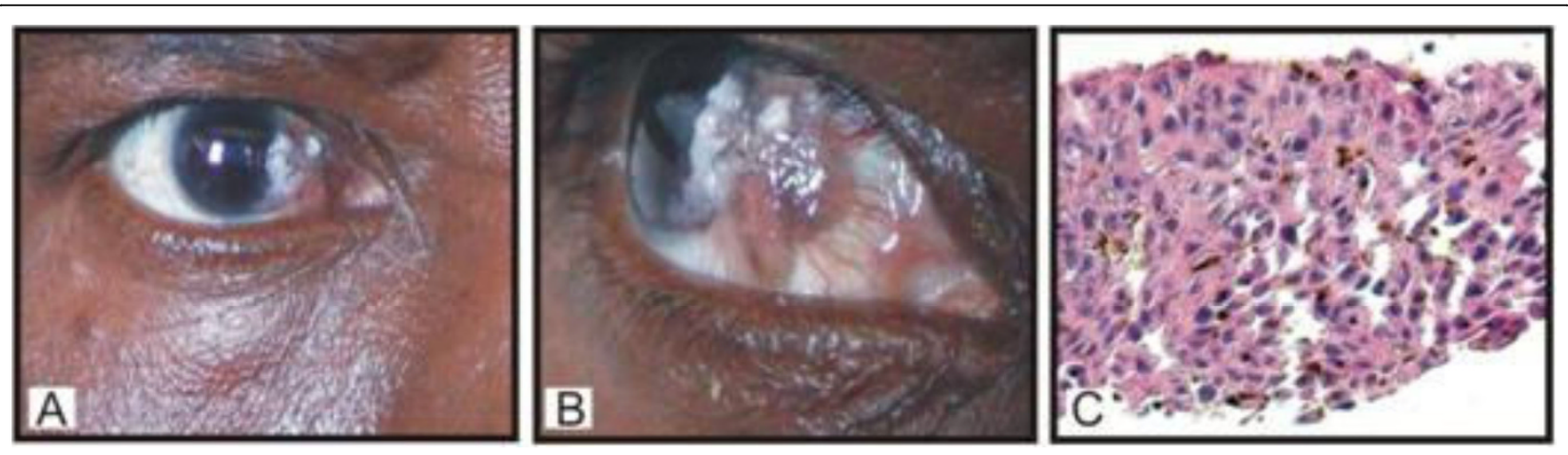

Figure 2 A. Representative photograph showing OSSN (A) and a closer view (B), C. H\&E staining showing features of in situ carcinoma characterized by full thickness changes in nuclear: cytoplasm ratio, nuclear pleomorphism, dyskeratotic cells, and presence of koilocytes. 
Table 2 Oncogenic viruses identified by PCR in patient samples

\begin{tabular}{|c|c|c|c|c|c|c|c|c|}
\hline Case \# & Diagnosis & HPV & EBV & KSHV & CMV & BK & JC & HSV $1 / 2$ \\
\hline 1 & OSSN & + & + & - & - & - & - & + \\
\hline 2 & Pterygium & + & + & + & + & - & - & + \\
\hline 3 & OSSN & + & + & + & + & - & - & + \\
\hline 4 & OSSN & + & + & + & - & - & - & + \\
\hline 5 & OSSN & + & + & - & + & - & - & + \\
\hline 6 & OSSN & + & + & + & + & - & - & + \\
\hline 8 & OSSN & + & + & + & - & - & - & + \\
\hline 9 & OSSN & + & + & - & - & - & - & + \\
\hline 11 & OSSN & + & + & + & - & - & - & - \\
\hline 12 & OSSN & + & + & + & - & - & - & - \\
\hline 13 & OSSN & $-/+$ & + & - & + & - & - & - \\
\hline 14 & OSSN & - & - & + & + & - & - & + \\
\hline 15 & Pterygium & - & + & + & + & - & - & + \\
\hline 16 & Pterygium & - & + & - & + & - & - & + \\
\hline 17 & Pterygium & - & + & + & - & - & - & + \\
\hline 18 & OSSN & - & + & + & + & - & - & + \\
\hline 19 & OSSN & - & + & + & - & - & - & - \\
\hline 21 & OSSN & - & + & + & - & - & - & - \\
\hline 22 & OSSN & - & + & - & - & - & - & - \\
\hline 23 & OSSN & - & + & + & + & - & - & + \\
\hline 24 & OSSN & - & + & + & + & - & - & - \\
\hline 25 & Pterygium & - & + & - & + & - & - & + \\
\hline 26 & Pterygium & + & - & + & + & - & - & - \\
\hline 27 & Pterygium & + & + & + & - & - & - & + \\
\hline 28 & OSSN & + & + & - & - & - & - & + \\
\hline 29 & OSSN & + & - & + & + & - & - & + \\
\hline 30 & Pterygium & + & + & - & + & - & - & - \\
\hline 31 & OSSN & + & + & + & + & - & - & + \\
\hline 32 & OSSN & - & + & - & + & - & - & + \\
\hline 33 & OSSN & + & - & + & + & - & - & + \\
\hline 34 & OSSN & + & + & + & - & - & - & - \\
\hline 35 & OSSN & + & - & + & - & - & - & - \\
\hline 36 & OSSN & + & + & - & + & - & - & + \\
\hline 37 & OSSN & + & - & + & + & - & - & + \\
\hline 38 & OSSN & + & + & + & + & - & - & + \\
\hline 39 & OSSN & + & + & + & + & - & - & + \\
\hline
\end{tabular}

Oncogenic viruses identified in each OSSN and pterygium patient as determined by PCR analysis. Most cases tested positive for HPV, EBV, KSHV and HSV. HPV results for samples 14-24 were intriguing since most were positive on IHC and ISH. None was positive for BK and JC.

\section{In situ hybridization analysis detected signals from multiple oncogenic viruses}

In situ hybridization was performed on sections from fresh paraffin-embedded tissue utilizing HPV-16 L1, EBV EBER, and KSHV ORF-72 specific oligonucleotide probes to corroborate the above results, the specific probes were detected using digoxigenin dd UTP label.
Table 3 Proportion of HPV types identified by PCR in OSSN and Pterygium tissues

\begin{tabular}{ccc}
\hline Virus Type & OSSN & Pterygium \\
\hline HPV-6 & $21 \%$ & 0 \\
\hline HPV-11 & $46 \%$ & $63 \%$ \\
\hline HPV-16 & $61 \%$ & $75 \%$ \\
\hline HPV-18 & $54 \%$ & $63 \%$ \\
\hline HPV-31 & $25 \%$ & 0 \\
\hline HPV-33 & $4 \%$ & 0 \\
\hline
\end{tabular}

Proportion of HPV types identified in patient samples by use of type specific HPV primers, HPV types $6,11,16,18,31$, and 33 . It is noted that HPV-11, 16 , and 18 were common in both OSSN and pterygia cases, with HPV-6, 31, and 33 only detected in OSSN cases.

However, we did not perform ISH for CMV, HSV $1 / 2$, and other types of HPV due to insufficient tissue sections. We observed punctate and diffuse nuclear signals indicative of integrated and episomal viral DNA genomes respectively, as seen in the representative Case \#31 photographs (Figure 3D-F and 3G-I). The punctate and episomal viral nuclear signals were more obvious in HPV samples. Importantly, no signals were observed with non specific probes or sense probes used as controls (Figure 3A-C). These probes for EBER-sense, KSHV-sense and HPV non-specific were used to clearly demonstrate that these signals obtained were due to the specific signals from the viral encoded transcripts and was unlikely to be due to non-specific interactions from cellular transcripts or deposited label. It should be noted that the intensity of the in situ hybridization staining was somewhat variable with some of the positive cells closer to the surface of the lesions with clear nuclear or perinuclear staining within the epithelial but little or no detectable signals in the subepithelial layers and the remaining epithelial tissue. For additional tissues diagnosed as OSSN, similar analyses were done and showed specific signals for the HPV-L1, EBV-EBER, and KSHV-ORF-72 for some of the cases. The results suggest similar patterns of infection with these viruses and correlated nicely with the PCR data from the samples obtained (Table 4).

\section{Immunohistochemical Analysis showed positive signals for viral antigens in OSSN tissues}

Based on PCR and in situ hybridization results in which we detected viral genes in the DNA extract and tissues of OSSN, we performed immunohistochemistry using specific antibodies to identify viral antigens known to be expressed by these viral agents in tissues. We noted specific signals with the antibodies to HPV- E6, EBVLMP1, and KSHV-LANA (Figure 4, panels D-I) from representative Case \# 31 compared to the controls. The cells showed strong dark staining of the nuclei suggesting positive signals for the viral antigen E6, and staining 
Table 4 Oncogenic viruses identified in each patient by IHC and ISH

\begin{tabular}{|c|c|c|c|c|c|c|c|c|c|c|}
\hline \multirow[t]{2}{*}{ Case \# } & \multirow[t]{2}{*}{ Diagnosis } & \multicolumn{3}{|c|}{ HPV } & \multicolumn{3}{|c|}{ EBV } & \multicolumn{3}{|c|}{ KSHV } \\
\hline & & IHC & ISH & PCR & $\mathrm{IHC}$ & ISH & PCR & $\mathrm{IHC}$ & ISH & PCR \\
\hline 1 & OSSN & - & - & + & + & + & + & + & + & - \\
\hline 2 & Pterygium & + & + & + & + & + & + & + & + & + \\
\hline 3 & OSSN & + & + & + & + & - & + & + & - & + \\
\hline 4 & OSSN & + & - & + & + & + & + & + & + & + \\
\hline 5 & OSSN & + & + & + & - & + & + & + & + & - \\
\hline 6 & OSSN & + & + & + & + & + & + & + & + & + \\
\hline 8 & OSSN & + & + & + & $+/-$ & $+/-$ & + & - & - & + \\
\hline 9 & OSSN & + & + & + & + & + & + & + & + & - \\
\hline 11 & OSSN & + & + & + & + & + & + & + & + & + \\
\hline 12 & OSSN & + & + & + & + & + & + & + & + & + \\
\hline 13 & OSSN & $-1+$ & $-/+$ & $-/+$ & + & - & + & + & + & - \\
\hline 14 & OSSN & + & + & - & + & + & - & + & - & + \\
\hline 15 & Pterygium & + & + & - & + & + & + & + & + & + \\
\hline 16 & Pterygium & + & + & - & + & - & + & + & + & - \\
\hline 17 & Pterygium & + & - & - & + & + & + & + & $+/-$ & + \\
\hline 18 & OSSN & + & + & - & + & + & + & + & + & + \\
\hline 19 & OSSN & + & + & - & + & + & + & + & + & + \\
\hline 21 & OSSN & + & + & - & + & + & + & + & + & + \\
\hline 22 & OSSN & + & + & - & + & + & + & + & + & - \\
\hline 23 & OSSN & + & - & - & + & + & + & + & $+/-$ & + \\
\hline 24 & OSSN & + & + & - & + & + & + & + & + & + \\
\hline 25 & Pterygium & + & $+/-$ & - & + & + & + & + & + & - \\
\hline 26 & Pterygium & + & + & + & + & + & - & + & - & + \\
\hline 27 & Pterygium & + & + & + & + & + & + & + & + & + \\
\hline 28 & OSSN & + & $+/-$ & + & + & + & + & + & + & - \\
\hline 29 & OSSN & + & + & + & + & + & - & + & + & + \\
\hline 30 & Pterygium & + & + & + & + & + & + & + & + & - \\
\hline 31 & OSSN & + & + & + & - & - & + & $+/-$ & $+/-$ & + \\
\hline 32 & OSSN & - & - & - & + & + & + & + & + & - \\
\hline 33 & OSSN & + & - & + & + & + & - & + & - & + \\
\hline 34 & OSSN & - & + & + & + & + & + & + & + & + \\
\hline 35 & OSSN & + & + & + & + & + & - & + & + & + \\
\hline 36 & OSSN & + & + & + & + & - & + & + & + & - \\
\hline 37 & OSSN & - & - & + & + & + & - & + & + & + \\
\hline 38 & OSSN & + & + & + & + & + & + & + & + & + \\
\hline 39 & OSSN & + & + & + & - & - & + & + & + & + \\
\hline
\end{tabular}

+/- Indeterminate

Oncogenic viruses identified in each patient by Immunohistochemistry and In situ hybridization. It is noted that for each of the samples analyzed for the specific viruses-HPV-16/18, EBV, and KSHV, there was high concordance in IHC and ISH. For each virus a column for PCR results has been added for comparison. Due to lack of specimen we were unable to test for the other viruses. No tissue samples were available for patients 7,10 , and 20 . for LMP1, and LANA respectively. The cells that were intact showed dramatic signals suggesting the presence of multiple viruses in this cancer. Positive immunostaining was largely confined to the nuclei of the infected superficial epithelial layers of the tissues for E6 and LANA but also showed signals throughout the cell membrane or in focused regions of the membrane as would be expected for LMP1. To determine the specificity of the signals immunohistochemistry controls were performed without primary antibody (Figure 4, Panels A-C) and using tissue sections demonstrated to be negative for EBV, KSHV, and HPV by PCR (Figure 4, Panels $\mathrm{J}-\mathrm{L}$ ). The results showed no detectable signals for any of the sections developed (Figure 4, panels A-C, and J-L respectively) and supports the presence of these 3 oncogenic viruses in the tissues tested that were diagnosed as OSSN in HIV patients.

\section{Multiple types of HPV were identified in individual patients}

Amplicons from PCR products were further purified and sequenced using the consensus primers GP5+/GP6+. We analyzed a 150-bp fragment of the L1 region of 36 cases for specific HPV types and variations. Using a 40 base sequence including the GP5+ priming site selected as the signature for each HPV type online BLAST sequence alignment algorithms of the L1 3' end. The results suggest that based on these analyses twenty six HPV types were identified, with HPV- 7, 13, 16, 18, 39, 43 , and 45 being the most common (Table 5). Importantly, all the tissues were positive for multiple HPV types based on the analyses. We identified nucleotide variations in the majority of samples. The variations were mainly missense and silent mutations whose significance in maintenance of the virus is yet to be determined (Figure 1B). However, we observed that for HPV 39, the L1 C6741T variation was similar to C6733T and C6903T [39] in cervical cancer in South American population, and for HPV 18, the L1 G6731A variation was similar in cervical cases in Africa at G6579A, G6749A, and G6917A, while for HPV16, the L1 T6650G and A6651C similarity was noted in cervical cancer cases from India at T6889G and A6667C [40], (Figure $5)$.

\section{Discussion}

A dramatic increase in OSSN has been noted in subSaharan Africa over the last 10 years in HIV population [1]. In Uganda there has been an increase in incidence especially among young people linked to HIV infection 


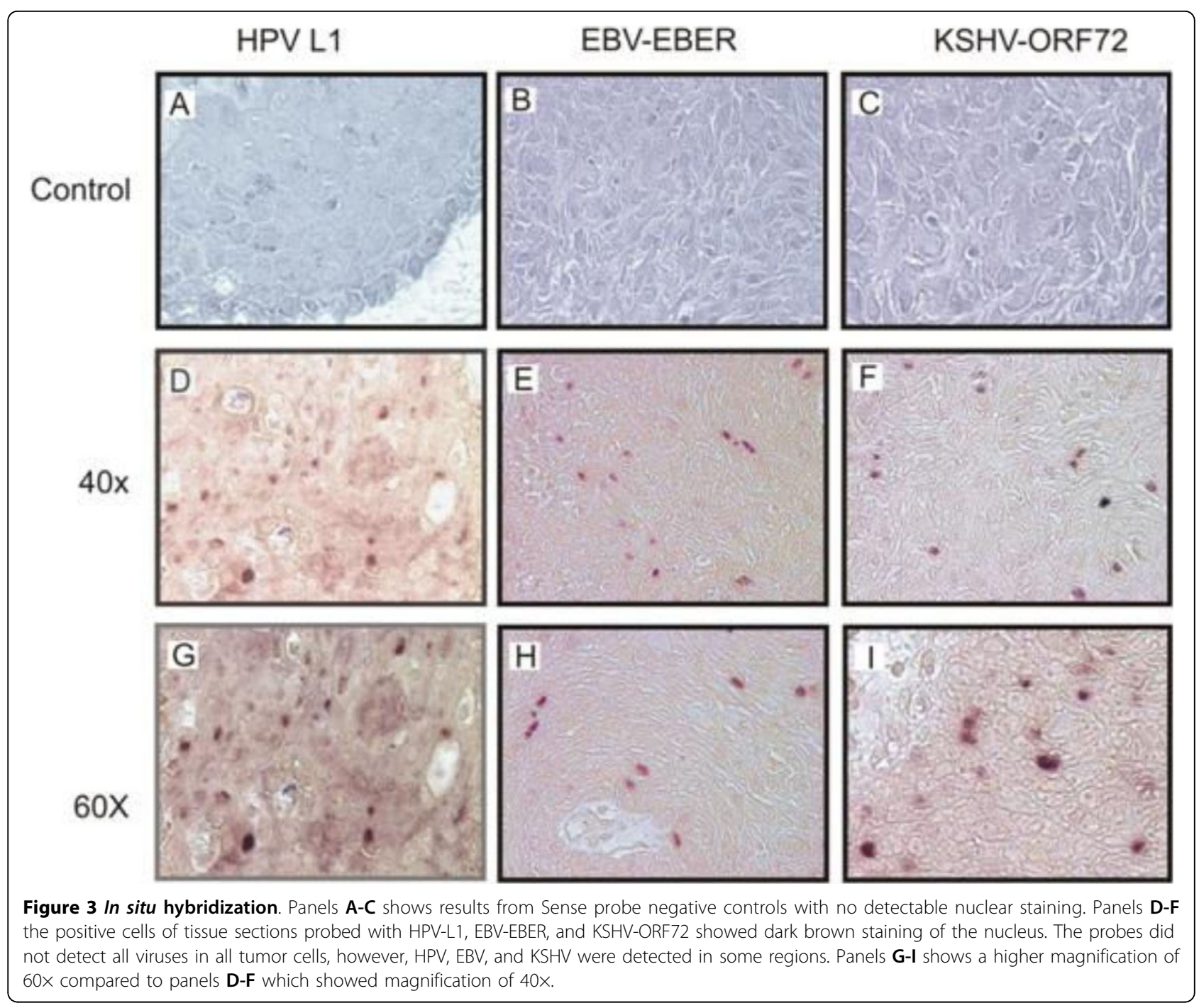

[6]. In Botswana, data from Princess Marina Hospital in Gaborone currently indicates a pronounced increase in incidence of OSSN in young HIV-1 infected individuals. This initial study concurrently detected the presence of multiple tumor viruses in OSSN tissues. For the first time we showed the presence of HPV, EBV, KSHV, and CMV in ocular tissues in HIV/AIDS patients. Association of viruses with human cancers have already been reported, such as KSHV with KS and PEL [41], EBV with primary CNS lymphoma [17], nasopharyngeal carcinoma [26], and Burkitt's lymphoma [22], HPV with cervical cancer [2], anal cancer [42], and testicular cancer [43], However, the level of contribution by HIV to the development of human malignancies remains unclear and is likely to be through several mechanisms.

Infection and establishment of latency are mediated by viral proteins expressed in infected cells. Importantly, the immunomodulatory mechanisms used by one virus may actually enhance or benefit the activity or replication of other viruses. Many of these viruses (for example, HPV, CMV, and EBV) are quite common in the human population [44], but do not always lead to development of malignancies in healthy individuals with a competent immune system. However, infection with HIV resulting in immunosuppression may eventually tip the balance in favor of the tumor viruses, leading to an increased risk of cancer in the immune compromised individuals. The localization of these oncogenic proteins in the OSSN tissues show association, however establishment of a causal effect by any of the viruses, or a multiple of the viruses in an HIV atmosphere has yet to be fully confirmed. Determining the pathways involved in the initiation and establishment of the cancers in HIV patients compared to non-HIV patients will give us a better understanding of the interplay of the different oncogenic viral proteins within the normal immune 

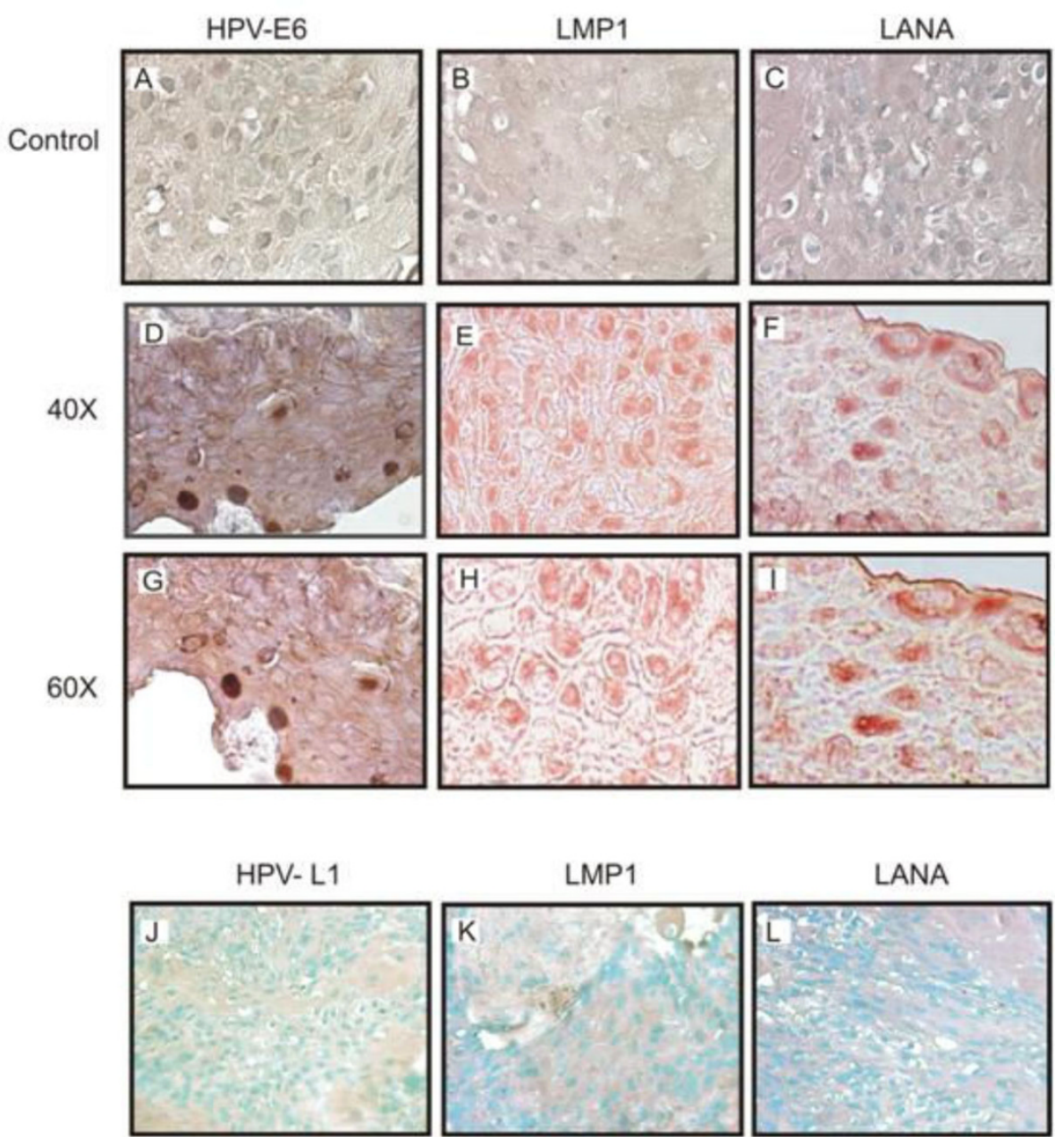

Figure 4 Representative Immunohistochemistry results of selected OSSN tissues. Panels A-C shows no nuclear staining in the negative controls, Panels D-F show positive cells as dark brown staining of the nucleus with HPV-E6 antibody, as well as positive staining for LMP1 and LANA using EBV-LMP1 hybridoma supernatant and KSHV-LANA specific antibody. Panels G-I shows a higher magnification of 60x compared to panels D-F taken at 40X. Panels $\mathbf{J}-\mathbf{L}$ are immunohistochemistry results for negative samples showing no detectable staining which would represent positive signals.

system and immunosuppressed system. Though we have shown the presence of these viral proteins in the OSSN tissue, some investigators have not identified viral sequences in squamous cell conjunctival carcinoma (SCCC) which has also increased in the HIV infected population and has been suspected of having viral etiology $[45,46]$. Therefore, more studies are clearly needed to fully establish a role for these viruses in OSSN.

The localization of different tumor viruses in similar tissue sections suggest that these viruses may functionally interact to contribute to the OSSN phenotype. Similar to our findings of HPV and EBV in ocular tissues, Prayitno reported that in 19 cervical carcinoma samples $89 \%$ were positive for HPV and 68\% were positive for EBV [47]. Nakamura et al suggested that HPV probably does not act alone in initiating ocular neoplasia, but that other factors including the ultraviolet light were involved [37]. Whereas studies involving HPV and cervical cancer have been associated with oncogenic HPV-16 and 18, our study identified HPV-6, 7,16, 18, 31, 45, and 97 in DNA from the OSSN and pterygia tissues as determined by PCR. Interestingly, we detected nucleotide sequences from HPV-1, 3, 7, 13, 16, 18, 29, 31, 33, 39, 40, 43, 44, 45, $55,59,61,68,70,74,77,85,8991$, and 97 by sequencing PCR amplicons from the different tissues. Some of the sequence alignments had scores greater than $80 \%$ with specific HPV types indicating presence of these HPV types or their variants in some of the samples. This suggests exposure to many types of HPV in this population, some of which are oncogenic, which with other factors may trigger cell proliferation leading to OSSN and other cancers in the immunocompromised patients. The 
Table 5 HPV Types detected in patient samples by sequencing using consensus primers GP5+/GP6+

\begin{tabular}{|c|c|}
\hline Case \# & HPV type \\
\hline 1 & $7,13,16,18,39,40,43,45,59,61,68,70,77,85,91,97$ \\
\hline 2 & $7,13,16,18,39,40,43,45,59,61,68,70,77,85,91,97$ \\
\hline 3 & $7,13,16,18,39,40,43,45,59,61,68,70,77,85,91,97$ \\
\hline 4 & $7,13,16,18,39,40,43,59,61,68,70,77,91,97$ \\
\hline 5 & $7,13,16,18,39,40,43,45,59,61,68,70,77,85,91,97$ \\
\hline 6 & $7,13,16,18,39,40,43,59,68,70,77,91,97$ \\
\hline 8 & $7,13,16,18,29,39,40,43,45,59,61,68,70,77,85,91,97$ \\
\hline 9 & $7,13,16,18,39,40,43,45,59,61,68,70,77,85,91,97$ \\
\hline 11 & $7,13,16,18,39,40,43,45,59,61,68,70,77,85,91,97$ \\
\hline 12 & $16,18,39,40,43,45,59,61,68,70,77,85,91,97$ \\
\hline 13 & $7,13,16,18,39,40,43,45,59,61,68,70,74,85,91,97$ \\
\hline 14 & $16,18,29,39,40,43,45,59,68,70,85,91,97$ \\
\hline 15 & $7,13,16,18,39,40,43,45,59,61,68,70,77,85,91,97$ \\
\hline 16 & $7,13,16,18,39,40,43,45,59,61,68,70,74,77,85,91,97$ \\
\hline 17 & $7,13,16,18,29,39,40,43,45,59,61,68,70,77,85,91,97$ \\
\hline 18 & $7,16,18,39,40,61,70,77,85,91,97$ \\
\hline 19 & $16,18,39,40,43,45,61,70,77,85,91,97$ \\
\hline 21 & $7,13,16,40,45,70,77,85$ \\
\hline 22 & $7,13,16,39,43,45,70,85$ \\
\hline 23 & $7,13,43,45,70,77,85$ \\
\hline 24 & $7,43,45,85$ \\
\hline 25 & $13,16,18,39,40,43,45,59,61,68,70,77,85,91,97$ \\
\hline 26 & $13,16,18,39,40,43,45,59,61,68,70,77,85,91,97$ \\
\hline 27 & $1,3,7,11,13,16,18,39,40,43,45,59,61,68,70,77,85,89,91,97$ \\
\hline 28 & $29,43,45,59,85$ \\
\hline 29 & $45,59,68,70,85$ \\
\hline 30 & $1,3,7,11,13,16,18,39,40,43,45,59,61,68,70,77,85,89,91,97$ \\
\hline 31 & $16,18,43,45,59,68,70$ \\
\hline 32 & $16,18,43,45,59,61,68,70$ \\
\hline 33 & $1,13,16,18,39,40,43,44,45,55,59,61,68$ \\
\hline 34 & $7,13,16,18,39,43,45,59,61,68,97$ \\
\hline 35 & $7,16,18,39,40,43,45,59,61,68,74$ \\
\hline 36 & $16,18,39,45,59,61,68,77,97$ \\
\hline 37 & $7,13,16,18,39,43,45,59,61,68,77,97$ \\
\hline 38 & $7,13,16,18,39,40,43,44,45,55,59,68,74,77,97$ \\
\hline 39 & $7,18,39,40,43,59,61,68,74,77,91,97$ \\
\hline
\end{tabular}

HPV types identified in patient samples by sequencing with the consensus primer GP5+/GP6+. The most commonly identified HPV type in both OSSN and pterygium tissues included the high risk HPV-18, 16, 45, 39, 59, and 68 .

selection pressure that may exist as a consequence of competition between opportunistic infections may further lead to mutations occurring in the HPV types as well as the other infectious agents. Interestingly, there was a significant amount of amino acid variation within the cases to suggest different HPV types when each sequence was aligned with the specific HPV prototype.
To corroborate the PCR results we performed in situ hybridization and immunohistochemistry studies. These results showed that in the invasive OSSN tissues the viruses were localized in similar tissue sections. Some of the viral genomes are likely to be integrated by their punctate signals and episomal viral DNA by their diffuse signal throughout the nucleus [24]. The number of cells positive for viral signals were modest, possibly a factor of the limited size of tissues tested, relatively small size of the tissue obtained for analysis, and lower sensitivity compared to PCR. Previous reports have suggested that infection with more than one HPV type enhances cervical cancer and oral squamous carcinoma [23]. Also, Mirzamani et al reported co-infections with EBV and HPV-16/18 in nasopharyngeal carcinoma (NPC) patients and concluded that both viruses were important in contributing to the pathogenesis of NPC [26]. It is not known if cases with OSSN without HIV infection had similar outcome with HPV and other viruses as we were unable to obtain these tissue samples. Moubayed et al reported HPV-6/11, HPV-16, and HPV-18 in a Tanzanian study, with the conclusion that it was HPV-16 and HPV-18 that was associated with OSSN [48]. They noted that the intensity of in situ hybridization was highly variable ranging from barely detectable to a few grains over some cells located near the surface of the lesions [48]. As in some of our hybridization results they noted nuclear or perinuclear staining within the epithelial lesions and a complete absence of hybridization signals in the subepithelial layers and the surrounding unaffected epithelium.

The significance of all the HPV types identified with respect to OSSN oncogenesis in individual patients, and specifically the infection with multiple oncogenic HPV types-both high risk and low risk, EBV, and KSHV viruses requires careful examination. Some studies have indicated that the oncogenic capacity of HPV variants may also differ between geographic regions based on HLA allele distribution in these populations [40]. The unknown impact of HLA allele differences, HPV variants, and other oncogenic viruses in this HIV-1 infected population is of significance and warrants further investigation.

In tropical countries secondary immunodeficiency attributable to chronic inflammation caused by parasitic or viral infections might contribute to tumorigenesis. The high frequency of coinfection of HPV, EBV, KSHV, CMV, and HIV in the OSSN patients may be a result of cooperative and complementary interactions of the viruses. In addition, we suggest that the disease might be more aggressive in HIV patients due to their immune dysfunction, abnormal cytokine and chemokine expression, growth factor production and exposure to ultraviolet rays. In this sample we cannot determine if the 


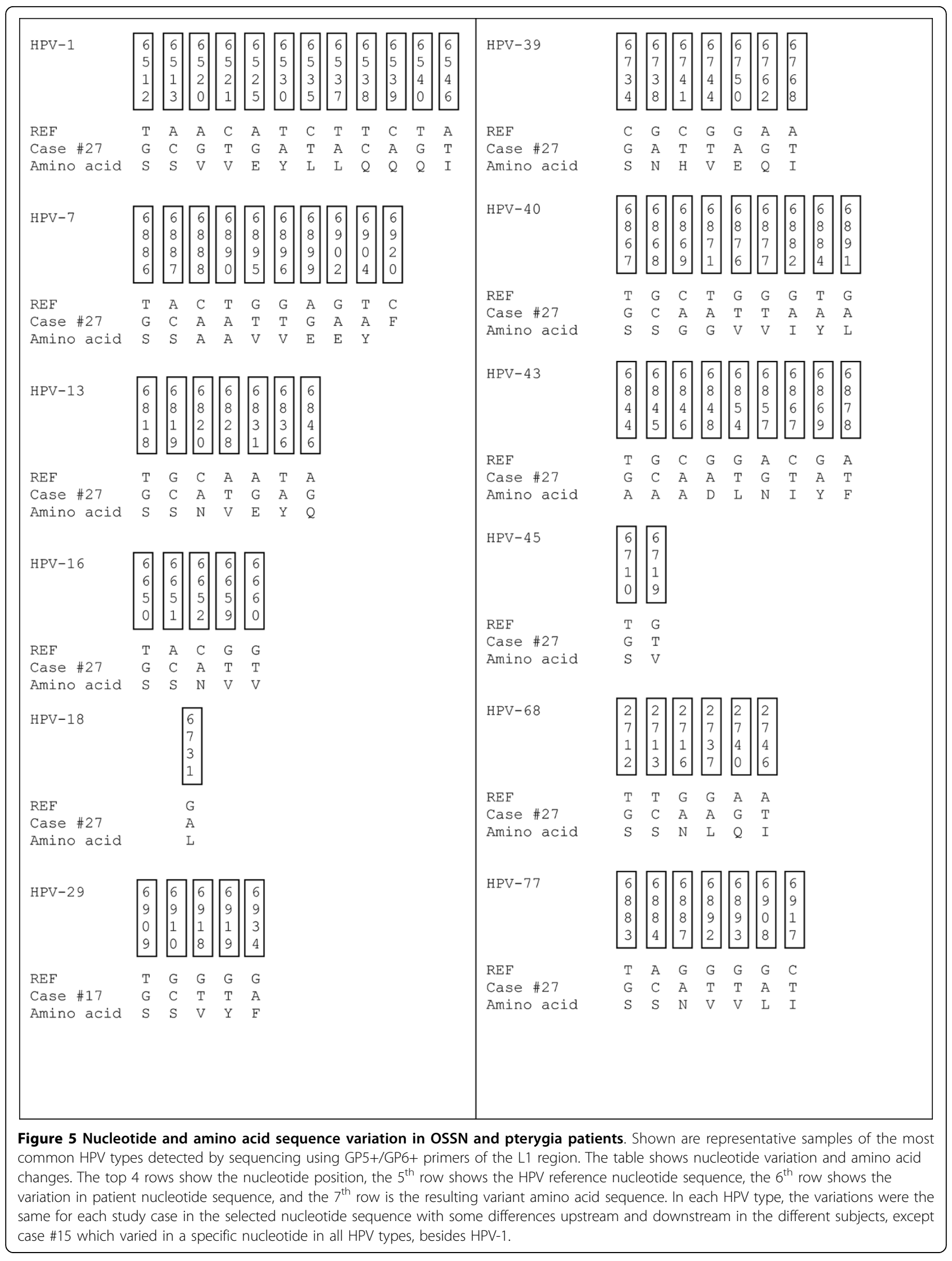


patients were initially infected with HPV, or HIV and other oncogenic viruses before occurrence of OSSN, or if some of the viruses were opportunistic infections as a result of OSSN disease or HIV infection. The effect of latency in ubiquitous viruses like EBV, HPV and high prevalence of sexually transmitted HSV and KSHV is not clear in this OSSN population. It has been reported, and we also note that the course of OSSN is more rapid in HIV infected patients and the occurrence is increasing in younger patients with HIV at a higher rate $[3,6]$. In HIV infected patients, it is not known at what stage OSSN occurs. Spitzer et al in a Malawi study reported that OSSN was the first detectable sign of HIV infection in the majority of cases [7].

\section{Conclusion}

This study investigating the link between oncogenic viruses in OSSN in the HIV population suggests that multiple viral agents may have a role in development of this disease. The interaction between different viral antigens and their regulatory activities in immunocompromised individuals will contribute to cell survival and proliferation in the infected cells. Clearly, further study is warranted to understand the molecular processes involved in the increased incidence of OSSN in the HIV population.

\section{Funding}

This work was supported by the UPENN Center for AIDS Research (P30-A1455008 to JH); the pilot project award to ESR and GB and the Botswana UPENN partnership in Gaborone, Botswana; Public Health awards from the National Cancer Institute of the National Institutes of Health (CA137894, CA138434, CA72150, CA91792, CA91792-S1, CA91792-S2, CA108461 to ESR); the National Institute of Allergy and Infectious Diseases (A167037 to ESR); from the National Institute of Dental and Craniofacial Research (DE17338 to ESR), and the Pennsylvania Department of Health (PA DOH Commonwealth Universal Research Enhancement Program) Tobacco Settlement grant to MF that "specifically disclaims responsibility for any analysis, interpretations or conclusions".

\section{Acknowledgements \\ The authors thank Dr. James Hoxie, Director UPENN CFAR program, Dr. Rameshwari Thakur of Botswana UPENN partnership, Ms. Tuelo Baitseng of Botswana UPENN partnership, Dr. Harvey Friedman, Director Botswana UPENN program. We would also like to extend special thanks to all the patients and physicians as well as the personnel at the Princess Marina Hospital without whom this study would not have been possible.}

\section{Author details}

'Department of Microbiology, and Abramson Comprehensive Cancer Center, Tumor Virology Program, University of Pennsylvania, 202A Johnson Pavilion, 3610 Hamilton Walk, Philadelphia, PA 19104-6076, USA. ${ }^{2}$ Pathology and
Laboratory Medicine, Founders Building, 6.058 HUP/4283, 6th Floor, Philadelphia, PA 19104-6076, USA. 'Botswana-University of Pennsylvania Partnership, The Children's Hospital of Philadelphia and the Center for AIDS Research, University of Pennsylvania, 3615 Civic Center Blvd, Suite 1202 ARC, Philadelphia, PA 19104-4318, USA. ${ }^{4}$ University of Botswana School of Medicine PBag 0022, Gaborone. ${ }^{5}$ Center for Clinical Epidemiology and Biostatistics, 832 Blockley Hall, 423 Guardian Dr. Philadelphia, PA 19104-6076, USA. ${ }^{6}$ Department of Microbiology, Kochi Medical School, Kohasu, Nankoku, Kochi, 783-8505, Japan.

\section{Authors' contributions}

KOS designed the study, conducted experiments, interpreted data and drafted the manuscript, MM conducted experiments, interpreted data and drafted the manuscript, MF performed microscopy and drafted the manuscript, APS recruited patients, collected samples and drafted manuscript, ON recruited patients, extracted patient tissues and drafted the manuscript, GB designed the study and drafted the manuscript, and ESR designed the study, interpreted data, drafted the manuscript, and supervised study. All authors have read and approved the final manuscript.

\section{Competing interests}

The authors declare that they have no competing interests.

Received: 6 November 2009 Accepted: 26 March 2010

Published: 26 March 2010

\section{References}

1. Kiire CA, Dhillon B: The aetiology and associations of conjunctival intraepithelial neoplasia. Br J Ophthalmol 2006, 90:109-113.

2. Munoz N, Bosch FX, de Sanjose S, Herrero R, Castellsague X, Shah KV, Snijders PJ, Meijer CJ: Epidemiologic classification of human papillomavirus types associated with cervical cancer. N Engl J Med 2003, 348:518-527.

3. Mahomed A, Chetty R: Human immunodeficiency virus infection, $\mathrm{BCl}-2$, p53 protein, and Ki-67 analysis in ocular surface squamous neoplasia. Arch Ophthalmol 2002, 120:554-558.

4. Basti S, Macsai MS: Ocular surface squamous neoplasia: a review. Cornea 2003, 22:687-704.

5. Lee GA, Hirst LW: Retrospective study of ocular surface squamous neoplasia. Aust N Z J Ophthalmol 1997, 25:269-276.

6. Kestelyn P, Stevens AM, Ndayambaje A, Hanssens M, Perre van de P: HIV and conjunctival malignancies. Lancet 1990, 336:51-52.

7. Spitzer MS, Batumba NH, Chirambo T, Bartz-Schmidt KU, Kayange P, Kalua K, Szurman P: Ocular surface squamous neoplasia as the first apparent manifestation of HIV infection in Malawi. Clin Experiment Ophthalmol 2008, 36:422-425.

8. McDonnell JM, McDonnell PJ, Mounts P, Wu TC, Green WR: Demonstration of papillomavirus capsid antigen in human conjunctival neoplasia. Arch Ophthalmol 1986, 104:1801-1805.

9. Ateenyi-Agaba C: Conjunctival squamous-cell carcinoma associated with HIV infection in Kampala, Uganda. Lancet 1995, 345:695-696.

10. Clifford GM, Gallus S, Herrero R, Munoz N, Snijders PJ, Vaccarella S, Anh PT, Ferreccio C, Hieu NT, Matos E, et al: Worldwide distribution of human papillomavirus types in cytologically normal women in the International Agency for Research on Cancer HPV prevalence surveys: a pooled analysis. Lancet 2005, 366:991-998.

11. Waddell KM, Downing RG, Lucas SB, Newton R: Corneo-conjunctival carcinoma in Uganda. Eye 2006, 20:893-899.

12. Panchapakesan J, Hourihan F, Mitchell P: Prevalence of pterygium and pinguecula: the Blue Mountains Eye Study. Aust N Z J Ophthalmol 1998, 26(Suppl 1):S2-5.

13. Detels R, Dhir SP: Pterygium: a geographical study. Arch Ophthalmol 1967, 78:485-491.

14. Sjo NC, von Buchwald C, Cassonnet P, Norrild B, Prause JU, Vinding T, Heegaard S: Human papillomavirus in normal conjunctival tissue and in conjunctival papilloma: types and frequencies in a large series. $\mathrm{Br} J$ Ophthalmol 2007, 91:1014-1015.

15. Tsai $Y Y$, Chang CC, Chiang CC, Yeh KT, Chen PL, Chang CH, Chou MC, Lee $\mathrm{H}$, Cheng YW: HPV infection and p53 inactivation in pterygium. Mol Vis 2009, 15:1092-1097 
16. Hirst LW, Axelsen RA, Schwab I: Pterygium and associated ocular surface squamous neoplasia. Arch Ophthalmol 2009, 127:31-32.

17. Cohen Jl: Epstein-Barr virus infection. N Engl J Med 2000, 343:481-492.

18. Schalling M, Ekman M, Kaaya EE, Linde A, Biberfeld P: A role for a new herpes virus (KSHV) in different forms of Kaposi's sarcoma. Nat Med 1995, 1:707-708.

19. Pyakurel P, Pak F, Mwakigonja AR, Kaaya E, Biberfeld P: KSHV/HHV-8 and HIV infection in Kaposi's sarcoma development. Infect Agent Cancer 2007, 2:4.

20. Mbulaiteye SM, Biggar RJ, Goedert JJ, Engels EA: Immune deficiency and risk for malignancy among persons with AIDS. J Acquir Immune Defic Syndr 2003, 32:527-533.

21. Shingadia D, Howard MR, Brink NS, Gibb D, Klein N, Tedder R, Novelli V: Kaposi's sarcoma and KSHV. Lancet 1995, 346:1359-1360.

22. Goldenberg D, Golz A, Netzer A, Rosenblatt E, Rachmiel A, Goldenberg RF, Joachims HZ: Epstein-Barr virus and cancers of the head and neck. Am J Otolaryngol 2001, 22:197-205.

23. Premoli-De-Percoco G, Ramirez JL, Galindo I: Correlation between HPV types associated with oral squamous cell carcinoma and cervicovaginal cytology: An in situ hybridization study. Oral Surg Oral Med Oral Pathol Oral Radiol Endod 1998, 86:77-81.

24. Yang YY, Koh LW, Tsai JH, Tsai CH, Wong EF, Lin SJ, Yang CC: Involvement of viral and chemical factors with oral cancer in Taiwan. Jpn J Clin Oncol 2004, 34:176-183.

25. Huang $H$, Reis $R$, Yonekawa $Y$, Lopes JM, Kleihues P, Ohgaki $H$ : Identification in human brain tumors of DNA sequences specific for SV40 large T antigen. Brain Pathol 1999, 9:33-42.

26. Mirzamani N, Salehian P, Farhadi M, Tehran EA: Detection of EBV and HPV in nasopharyngeal carcinoma by in situ hybridization. Exp Mol Pathol 2006, 81:231-234.

27. Palazzi MA, Erwenne CM, Villa LL: Detection of human papillomavirus in epithelial lesions of the conjunctiva. Sao Paulo Med J 2000, 118:125-130.

28. Frisch M, Biggar RJ, Goedert JJ: Human papillomavirus-associated cancers in patients with human immunodeficiency virus infection and acquired immunodeficiency syndrome. J Natl Cancer Inst 2000, 92:1500-1510.

29. Brouchet L, Valmary S, Dahan M, Didier A, Galateau-Salle F, Brousset $P$, Degano $B$ : Detection of oncogenic virus genomes and gene products in lung carcinoma. Br J Cancer 2005, 92:743-746.

30. Hoshikawa Y, Satoh Y, Murakami M, Maeta M, Kaibara N, Ito H, Kurata T, Sairenji T: Evidence of lytic infection of Epstein-Barr virus (EBV) in EBVpositive gastric carcinoma. J Med Virol 2002, 66:351-359.

31. Johnson G, Nelson S, Petric M, Tellier R: Comprehensive PCR-based assay for detection and species identification of human herpesviruses. J Clin Microbiol 2000, 38:3274-3279.

32. Mizobuchi S, Sakamoto H, Tachimori $Y$, Kato H, Watanabe H, Terada M: Absence of human papillomavirus-16 and -18 DNA and Epstein-Barr virus DNA in esophageal squamous cell carcinoma. Jpn J Clin Oncol 1997, 27:1-5.

33. Holman CJ, van Burik JA, Hinrichs SH Jr, Balfour HH Jr: Specific detection of human BK polyomavirus in urine samples of immunocompromised patients. Clin Diagn Lab Immunol 2003, 10:66-69.

34. Cai QL, Knight JS, Verma SC, Zald P, Robertson ES: EC5S ubiquitin complex is recruited by KSHV latent antigen LANA for degradation of the VHL and p53 tumor suppressors. PLoS Pathog 2006, 2:e116.

35. de Roda Husman AM, Walboomers JM, van den Brule van den AJ, Meijer CJ, Snijders PJ: The use of general primers GP5 and GP6 elongated at their $3^{\prime}$ ends with adjacent highly conserved sequences improves human papillomavirus detection by PCR. J Gen Virol 1995, 76(Pt 4):1057-1062.

36. Baay MF, Quint WG, Koudstaal J, Hollema H, Duk JM, Burger MP, Stolz E, Herbrink P: Comprehensive study of several general and type-specific primer pairs for detection of human papillomavirus DNA by PCR in paraffin-embedded cervical carcinomas. J Clin Microbiol 1996, 34:745-747.

37. Nakamura Y, Mashima Y, Kameyama K, Mukai M, Oguchi Y: Detection of human papillomavirus infection in squamous tumours of the conjunctiva and lacrimal sac by immunohistochemistry, in situ hybridisation, and polymerase chain reaction. Br J Ophthalmol 1997, 81:308-313

38. Lu J, Verma SC, Murakami M, Cai Q, Kumar P, Xiao B, Robertson ES: Latency-associated nuclear antigen of Kaposi's sarcoma-associated herpesvirus (KSHV) upregulates survivin expression in KSHV-Associated
B-lymphoma cells and contributes to their proliferation. J Virol 2009, 83:7129-7141.

39. Stewart AC, Eriksson AM, Manos MM, Munoz N, Bosch FX, Peto J, Wheeler CM: Intratype variation in 12 human papillomavirus types: a worldwide perspective. J Virol 1996, 70:3127-3136.

40. Pande S, Jain N, Prusty BK, Bhambhani S, Gupta S, Sharma R, Batra S, Das BC: Human papillomavirus type 16 variant analysis of E6, E7, and L1 genes and long control region in biopsy samples from cervical cancer patients in north India. J Clin Microbiol 2008, 46:1060-1066.

41. Cook-Mozaffari P, Newton R, Beral V, Burkitt DP: The geographical distribution of Kaposi's sarcoma and of lymphomas in Africa before the AIDS epidemic. Br J Cancer 1998, 78:1521-1528.

42. Salit IE, Tinmouth J, Chong S, Raboud J, Diong C, Su D, Sano M, Lytwyn A, Chapman W, Mahony J: Screening for HIV-associated anal cancer: correlation of HPV genotypes, p16, and E6 transcripts with anal pathology. Cancer Epidemiol Biomarkers Prev 2009, 18:1986-1992.

43. Akre O, Lipworth L, Tretli S, Linde A, Engstrand L, Adami HO, Melbye M, Andersen A, Ekbom A: Epstein-Barr virus and cytomegalovirus in relation to testicular-cancer risk: a nested case-control study. Int J Cancer 1999, 82:1-5.

44. Trottier $H$, Burchell AN: Epidemiology of mucosal human papillomavirus infection and associated diseases. Public Health Genomics 2009, 12:291-307.

45. Waddell KM, Lewallen S, Lucas SB, Atenyi-Agaba C, Herrington CS, Liomba G: Carcinoma of the conjunctiva and HIV infection in Uganda and Malawi. Br J Ophthalmol 1996, 80:503-508.

46. Feng H, Taylor JL, Benos PV, Newton R, Waddell K, Lucas SB, Chang Y, Moore PS: Human transcriptome subtraction by using short sequence tags to search for tumor viruses in conjunctival carcinoma. J Virol 2007, 81:11332-11340.

47. Prayitno A: Cervical cancer with human papilloma virus and Epstein Barr virus positive. J Carcinog 2006, 5:13.

48. Moubayed P, Mwakyoma H, Schneider DT: High frequency of human papillomavirus $6 / 11,16$, and 18 infections in precancerous lesions and squamous cell carcinoma of the conjunctiva in subtropical Tanzania. Am J Clin Pathol 2004, 122:938-943.

doi:10.1186/1750-9378-5-6

Cite this article as: Simbiri et al:: Multiple oncogenic viruses identified in Ocular surface squamous neoplasia in HIV-1 patients. Infectious Agents and Cancer 2010 5:6.

\section{Submit your next manuscript to BioMed Central and take full advantage of:}

- Convenient online submission

- Thorough peer review

- No space constraints or color figure charges

- Immediate publication on acceptance

- Inclusion in PubMed, CAS, Scopus and Google Scholar

- Research which is freely available for redistribution

Submit your manuscript at www.biomedcentral.com/submit
C Biomed Central 